\title{
Ghrelin, resistin and insulin in obese diabetic women in Wad-Madani, Sudan
}

\author{
Mohammed Aliya Elamin ${ }^{1}$, Sukkar Mohammed Youseif, Hamid Azhari Mohammed ${ }^{3}$
}

1. Department of Medical Physiology, Faculty of Medicine, King Faisal University, Alahsa, Saudi Arabia.

2. Department of Physiology, Nile College, Khartoum, Sudan.

3. Department of Molecular Biology, Institute of Cancer, University of Gezira, Madani, Sudan.

\begin{abstract}
Background: Obesity in the Sudan is increasing at alarming rate with the tendency of reaching an epidemic proportion in women. It is commonly associated with type 2 diabetes (T2D). Some adipokine hormones such as resistin are associated with obesity.
\end{abstract}

Objectives:. To study how the levels of resistin, ghrelin and insulin are associated with obesity,fat distribution and (T2D) and to ascertain any interrelationships between them.

Subjects and methods: 150 women, age $\geq 18$ years old, resident in Wad-Madani town, Sudan were participated in the study. They were divided into 3 groups according to body mass index (BMI) value: I (normal weight), II (overweight) and III (obese diabetic). Fasting serum resistin and ghrelin concentrations were measured using ELISA method. Insulin levels were determined by radioimmunoassay(RIA).

Results: The mean \pm SD levels of resistin $5.80 \pm 4.91 \mathrm{ng} / \mathrm{mL}$, Ghrelin107.60 $\pm 26.67 \mathrm{pg} / \mathrm{M}$ and Insulin $11.92 \pm 8.54 \mathrm{mLU} / \mathrm{ml} \mathrm{in}$ obese diabetic were found to be greater than in normal or overweight women.In normal weight values were $3.07 \pm 2.15 \mathrm{ng} /$ $\mathrm{mL} 83.30 \pm 13.38 \mathrm{pg} / \mathrm{mL}$, and $6.62 \pm 6.77 \mathrm{mLU} / \mathrm{ml}$ for resistini, ghrelin and Insulin, respectively. Values for overweight women $3.64 \pm 2.63 \mathrm{pg} / \mathrm{mL} 90 \pm 17.35 \mathrm{pg} / \mathrm{mL}$ and $8.13 \pm 7.54 \mathrm{mLU} / \mathrm{ml}$ for resistin, ghrelin and insulin respectively.

Conclusions and recommendations: Increased BMI, waist circumference (WC) and hormones (ghrelin and resistin) were associated with insulin resistance.Further studies are needed to accept or refute these findings.

Keywords: Obesity, BMI, WC, T2D, ghrelin, resistin and insulin resistence (IR).

DOI: https://dx.doi.org/10.4314/ahs.v20i1.32

Cite as: Elamin MA, Youseif SM, Mohammed HA. Ghrelin, resistin and insulin in obese diabetic women in Wad-Madani, Sudan Afri Health Sci. 2020;20(1):266-76. https:// dx.doi.org/10.4314/abs.v20i1.32

\section{Introduction}

Obesity is a community health problem accompanied by"metabolic syndrome," which is stipulated to be affecting over one billion adults worldwide. ${ }^{1}$ There is a reported dramatic rise in global obesity resulting in an increase in morbidity and mortality in humans, with morbid obesity being regarded as a real threat to health. ${ }^{2}$ Metabolic complications of obesity in humans are associated with increased risks of various diseases such as insulin resistance, cardiovascular diseases, hypertension and cer-

\section{Corresponding author:}

Mohammed Aliya Elamin,

Department of Medical Physiology,

Faculty of Medicine, King Faisal University,

Alahsa, Saudi Arabia.

Tel: +966557582831

Email: aelbadawi@kfu.edu.sa tain type of cancers as earlier reported. ${ }^{1}$ All of these have evolved as a result of unhealthy life styles. Generally, obesity is characterized by the excessive accumulation of fat in the adipose tissue which happens to be the source of several cytokines. The tissue act as an endocrine gland that shots hormones resistin into the blood to participate in their potency imbodiment in Insulin resistance and diabetes. ${ }^{3}$ Inclusive of resistin, ghrelin and insulin also play vital roles in insulin resistence as they are fascilitators in the pathogenesis of obesity. Researchers have demonstrated substantially that resistin provides the link between obesity, inflammation and atherosclerosis. Resistin belongs to a family of cysteine-rich proteins which have been linked to insulin resistance initially in rodents and then in humans. ${ }^{4}$ Resistin-like molecules are indicated to be presumptive adipocyte-derived signaling polypeptide generated in monocytes and acrophages associated with insulin resistance. Other studies postulate that resistin acts by decreasing insulin-stimulated glucose up take. $^{2}$

\footnotetext{
African $\quad$ C 2020 Elamin MA et al. Licensee African Health Sciences. This is an Open Access article distributed under the terms of the Creative commons Attribution License Health Sciences (https://creativecommons.org/licenses/BY/4.0), which permits unrestricted use, distribution, and reproduction in any medium, provided the original work is properly cited.
} 
Recent studies revealed that significantly increase in resistin levels were observed in obese patient than those in normal body mass subjects. ${ }^{3}$ Whereas, ghrelin, a gut homone, is an appetite regulating hormone secreted during fasting by gastrointestinal endocrine cells and plays an important role in the coordination of energy balance and weight regulation. ${ }^{4}$ At the release of ghrelin, there is an activation of the growth hormone secretagogue receptor (GHS-R) within the anterior lobe of the pituitary gland, inducing the amount of food intake. ${ }^{5}$ unacylated ghrelin plays an important role in increasing fat tissue by reducing fat oxidation and encouraging the motility and gastric emptying. This process may imply a local effect and central mechanisms as well. ${ }^{6}$ His secretion levels are influenced by body fat and pubertal stage ${ }^{4,7}$ where they enhanced obesity and T2D in obese subjects. ${ }^{8}$ Moreover, the reduction occurs in ghrelin concentration may be related to the high caloric intake, whereas a reduction in body weight in obese patients caused elevation in ghrelin concentration level.This procedure could interpret the mark reduction of body weight in obese subjects. Insulin resistance and hyperinsulinemia are associated with ghrelin concentrations, which may constitute a part of the feedback mechanism by which body weight is regulated. ${ }^{9}$ Grehlin was reported as one of the candidate genes responsiuble for obesity and T2D. ${ }^{10}$

Obesity and T2D in Sudan are increasing at alarming rate and have tendency to reach epidemic proportion in women. The objectives of this study was to estimate the levels of these hormones and their associations with Insulin resistence in obese diabetic women.

\section{Subjects and method}

\section{Ethical consideration}

All participants gave written consent for participation in the study and informed about the aim of the experiment. The study protocol was approved by the University of Gezira, Faculty of Medicine, to protect the rights and welfare of the human subjects (Sudan, acceptance letter No.0254/100/2012).

\section{Study subjects and experimental design}

A total of 150 women living in Wad-Madani, Sudan were used for the study. They were 18 years of age and above, divided into three groups based on their BMI classification. Anthropometric parameters such as age, height and weight were ascertained. WC was measured using cutoffs as recommended by WHO 2018. ${ }^{11}$ Thus the women par- ticipants were divided into three groups according to the following: Low risk of disease $\leq 79 \mathrm{~cm}$, increased risk of disease $80-87 \mathrm{~cm}$ and substantially increased risk of disease $\geq 88 \mathrm{~cm}$. Body mass indices (BMI) were calculated according to BMI cutoffs proposed by the National Institutes of Health as follows: Underweight less than18.5, normal weight were between 18.5 to 24.9 , 25.0-29.9 being overweight while 30.0 - 34.9 was obesity class one, and 35.0 - 39.9 Obesity class 2 . Obesity class 3 were women with $\mathrm{BMI} \geq 40.0 .^{11}$

Blood samples were collected for hormonal analysis from the volunteering women. We excluded pregnant women, age $<18$ years old, chronic medical or psychiatric illness (with exception of obesity related diseases) and user of psychiatric drugs.

\section{Biological material preparation and determination of hormonal plasma concentration}

A trained nurse assisted with blood sample collection. After overnight fasting, blood samples from them were collected and put in heparinized test tubes. Plasma was separated by centrifugation at $(1000 \mathrm{~g}, 15 \mathrm{~min}$.) after which samples were divided into several portions and stored at $-70^{\circ} \mathrm{C}$ for future use.

Resistin and ghrelin levels were determined using ELISA. The hormonal concentrations in plasma were determined by immunoenzymatic methods using Human Quantikine ELISA Kit (R\&DSystems, USA) according to the manufacturer's guidlines. The insulin level was determined by radioimmunoassay ( RIA). This technique, using (IMK-414, China) kit according to the manufacturer's guidelines. The standards of the kit have insulin values ranging from 5 to $160 \mathrm{mlU} / \mathrm{L}$.

\section{Statistical analysis}

Data was recorded and analyszed using SPSS version 16.0. Independent samples t-test and pearson correlation coefficient were used to determine significance between relationships and comparison of the hormone levels. Differences among groups were compared by using one way ANOVA and least significant differences (LSD) for comparing means among hormonal levels, BMI and WC.

\section{Results}

The present study revealed a highly positive significant correlation between the (BMI) and the WC of the participants.Table: 1 illustrates the mean of BMI, age and WC of the study groups 
Table 1 : Mean BMI, age and WC of the three study groups

\begin{tabular}{|l|l|l|l|l|}
\hline Group numbe & Mean BMI \pm SD & Mean age \pm SD & Mean WC \pm SD & \\
\hline Normal weight & $22.01 \pm 2.09$ & $36.68 \pm 13.50$ & $90.46 \pm 6.40$ & \\
\hline Overweight & $27.26 \pm 1.96$ & $40.12 \pm 11.31$ & $104.04 \pm 9.11$ & \\
\hline Obese diabetic & $37.95 \pm 10.21$ & $53.52 \pm 12.55$ & $110.5 \pm 11.19$ & \\
\hline
\end{tabular}

Table 2 : Shows differences among hormonal levels, BMI and WC in study participants by using one way ANOVA test

\begin{tabular}{|l|c|c|c|l|c|l|}
\hline $\begin{array}{l}\text { Source of } \\
\text { variations }\end{array}$ & $\begin{array}{c}\text { Sum of } \\
\text { square } \\
\text { (SS) }\end{array}$ & $\begin{array}{c}\text { Square } \\
(\mathrm{df})\end{array}$ & $\begin{array}{c}\text { Means } \\
\text { of } \\
\text { squares } \\
\text { (MS) }\end{array}$ & $\begin{array}{l}\text { Calculated } \\
\text { F-value }\end{array}$ & $\begin{array}{c}\text { Critical } \\
\text { F-value }\end{array}$ & P value \\
\hline Between groups & 53.25 & 2 & 26.6 & 30.2 & 2.996 & $\mathrm{p}=0.05^{*}$ \\
\hline Within groups & 129.9 & 147 & 0.88 & & & \\
\hline Total hormomes & 183.15 & 149 & & & & \\
\hline $\begin{array}{l}\text { Source of } \\
\text { variations }\end{array}$ & $\mathrm{SS}$ & $\mathrm{df}$ & $\mathrm{MS}$ & $\begin{array}{l}\text { Calculated F- } \\
\text { value }\end{array}$ & $\begin{array}{c}\text { Critical F- } \\
\text { value }\end{array}$ & $\mathrm{P}$ value \\
\hline Between groups & 136 & 2 & 68 & 75.6 & 2.996 & $\mathrm{p}=0.05^{*}$ \\
\hline Within groups & 133.4 & 147 & 0.90 & & & \\
\hline Total WC & 269.4 & 149 & & & & $\mathrm{P}$ value \\
\hline $\begin{array}{l}\text { Source of } \\
\text { variations }\end{array}$ & $\mathrm{SS}$ & $\mathrm{df}$ & $\mathrm{MS}$ & $\begin{array}{l}\text { Calculated F- } \\
\text { value }\end{array}$ & $\begin{array}{l}\text { Critical F- } \\
\text { value }\end{array}$ \\
\hline Between groups & $60{ }^{\prime} 63$ & 2 & 30.315 & 43.3 & 2,996 & $\mathrm{p}=0.05^{*}$ \\
\hline Within groups & 102.52 & 147 & 0.7 & & & \\
\hline Total BMI & 163.15 & 149 & & & & \\
\hline
\end{tabular}

Table :2, demonstrates differences among hormonal levels, BMI and WC in study participants by using one way
ANOVA test and LSD for comparing means between and within groups. 
Table: 3. Comparison of the mean ghrelin, resistin and insulin levels in the study groups, analysing by independent samples $t$ test

\begin{tabular}{|c|c|c|c|c|c|c|}
\hline Hormone & Normal weight & Mean \pm SD & $\begin{array}{l}\text { Over- } \\
\text { weight }\end{array}$ & $\begin{array}{ll}\text { Means } & \pm \\
\text { SD } & \end{array}$ & t-test & value P- \\
\hline Ghrelin(pg/mL) & \multirow{3}{*}{$\mathrm{N}=50$} & $83.30 \pm 13.38$ & \multirow[t]{3}{*}{$\mathrm{N}=50$} & $\begin{array}{l}90.00 \pm 17.3 \\
5\end{array}$ & 9.622 & $0.000 * *$ \\
\hline Resistin(ng/mL) & & $3.07 \pm 2.15$ & & $3.64 \pm 2.63$ & 2.162 & 0.240 \\
\hline Insulin(mLU/mL) & & $6.62 \pm 6.77$ & & $8.13 \pm 7.54$ & 1.047 & 0.297 \\
\hline Hormone & Normal weight & Mean \pm SD & $\begin{array}{l}\text { Obese } \\
\text { diabetic }\end{array}$ & Mean \pm SD & t-test & $P$ value - \\
\hline Ghrelin(pg/mL) & \multirow[t]{3}{*}{$\mathrm{N}=50$} & $83.30 \pm 13.38$ & \multirow[t]{3}{*}{$\mathrm{N}=50$} & $\begin{array}{l}107.60 \pm 26 . \\
67\end{array}$ & 4.578 & $.000 * *$ \\
\hline Resistin(ng/mL) & & $3.07 \pm 2.15$ & & $5.80 \pm 4.91$ & 5.758 & $.000 * *$ \\
\hline $\operatorname{Insulin}(\mathrm{mLU} / \mathrm{mL})$ & & $6.62 \pm 6.77$ & & $11.92 \pm 8.54$ & 3.441 & $.001 * *$ \\
\hline Hormone & Over-weight & Means \pm SD & $\begin{array}{l}\text { Obese } \\
\text { diabetic }\end{array}$ & Means \pm SD & t-test & P-value \\
\hline Ghrelin(pg/mL) & \multirow[t]{3}{*}{$\mathrm{N}=50$} & $90.00 \pm 17.37$ & \multirow[t]{3}{*}{$\mathrm{N}=50$} & $\begin{array}{l}107.60 \pm 26 . \\
67\end{array}$ & -3.302 & $.001 * *$ \\
\hline Resistin(ng/mL) & & $3.64 \pm 2.63$ & & $5.80 \pm 4.91$ & 3.911 & $.000 * *$ \\
\hline $\operatorname{Insulin}(\mathrm{mLU} / \mathrm{mL})$ & & $8.13 \pm 7.54$ & & $11.92 \pm 8.54$ & 2.359 & $.020 * *$ \\
\hline
\end{tabular}

Whereas, Table (3) demonstrates the comparison be- normal weight, overweight and obese diabetic. Differenctween the mean levels of ghrelin, resistin and insulin in es among means level of hormones across groups were compared as shown in Table: 2

Table 4: Correlations of the hormones with the BMI and WC of the study groups.

\begin{tabular}{|c|c|c|c|c|c|}
\hline Groups & parameters & correlations & Insulin & ghrelin & Resistin \\
\hline \multirow[t]{4}{*}{ Normal weight } & \multirow[t]{2}{*}{ BMI } & $\mathrm{R}$ & -.067 & -.137 & .201 \\
\hline & & $P$ & .644 & .020 & .162 \\
\hline & \multirow[t]{2}{*}{$\mathrm{WC}$} & $\bar{R}$ & -.063 & .034 & .034 \\
\hline & & $\mathrm{P}$ & .665 & .813 & .813 \\
\hline \multirow[t]{4}{*}{ Overweight } & \multirow[t]{2}{*}{ BMI } & $\mathrm{R}$ & .059 & .124 & -.039 \\
\hline & & $\mathrm{P}$ & .685 & .391 & .786 \\
\hline & \multirow[t]{2}{*}{ WC } & $\mathrm{R}$ & -.209 & .083 & -.041 \\
\hline & & $\mathrm{P}$ & .146 & .565 & .777 \\
\hline \multirow[t]{4}{*}{ Obese diabetes type 2} & \multirow[t]{2}{*}{ BMI } & $\mathrm{R}$ & -.072 & .047 & -.097 \\
\hline & & $\mathrm{P}$ & .621 & .748 & .502 \\
\hline & \multirow[t]{2}{*}{$\mathrm{WC}$} & $\mathrm{R}$ & -.016 & .022 & .022 \\
\hline & & $\mathrm{P}$ & .910 & .881 & .881 \\
\hline
\end{tabular}


However, Table (4) shows the correlations of the measured hormones with the BMI and WC of the study groups. Significant difference $(\mathrm{P} \geq 0.05)$ were registered among insulin, resistin and ghrelin in the different groups. Contarary, both resistin and insulin were insignificant in overweight and normal weight when compared within group. There are significant correlations registered for resistin and ghrelin in overweight group when compared across different study groups.
Examing, WC in normal weight and overweight women revealed that, there is overlap of the scatter of insulin values and there is no significant difference between them $(\mathrm{p}=0.297)$. This indicatesthat WC does not play a role in these groups. The correlation between the insulin hormone and WC in over weight and obese diabetic women revealed that, the hormone has significant difference when the two groups were compared $(p=.020)$.

Table: 5 Correlation Samples of studied hormone in different study subjects

\begin{tabular}{|l|l|l|l|}
\hline Body weight & Pair & $\mathrm{r}$ & $\mathrm{P}$ \\
\hline Normal weight & Insulin Vs Grehlin & .091 & .528 \\
\cline { 2 - 4 } & Insulin Vs Resistin & .125 & .388 \\
\cline { 2 - 4 } & Grehlin Vs Resistin & -.001 & .996 \\
\hline \multirow{5}{*}{ Overweight } & Insulin Vs Grehlin & -.224 & .117 \\
\cline { 2 - 4 } & Insulin Vs Resistin & -.278 & .051 \\
\cline { 2 - 4 } & Grehlin Vs Resistin & -.085 & .556 \\
\hline Obese Diabetic & Insulin Vs Grehlin & .025 & .865 \\
\cline { 2 - 4 } & Insulin Vs Resistin & -.017 & .904 \\
\cline { 2 - 4 } & rehlin Vs Resistin & 098 & .498 \\
\hline
\end{tabular}

Table (5) shows the correlation coefficient among the studied hormones when we studied each versus another in all groups. In the present study six pairs of the hormonal correlations were obtained. No significant correlation, were registered for any pairs versus each other in normal weight overweight and obese diabetic subjects .Nevertheless, the mean insulin levels in the overweight is slightly higher than in normal weight subjects but the difference is insignificant, and still within the normal non-diabetic range.However, the mean insulin level is significantly higher in obese diabetic subjects when compared with both overweight and lean control subjects. Fig. 1 (A and C) shows the correlation between the insulin, BMI and WC in normal weight and overweight women whereas, Fig. 1 (B and D), illustrate the correlation between insulin, BMI and WC in overweight and obese diabetic groups. 

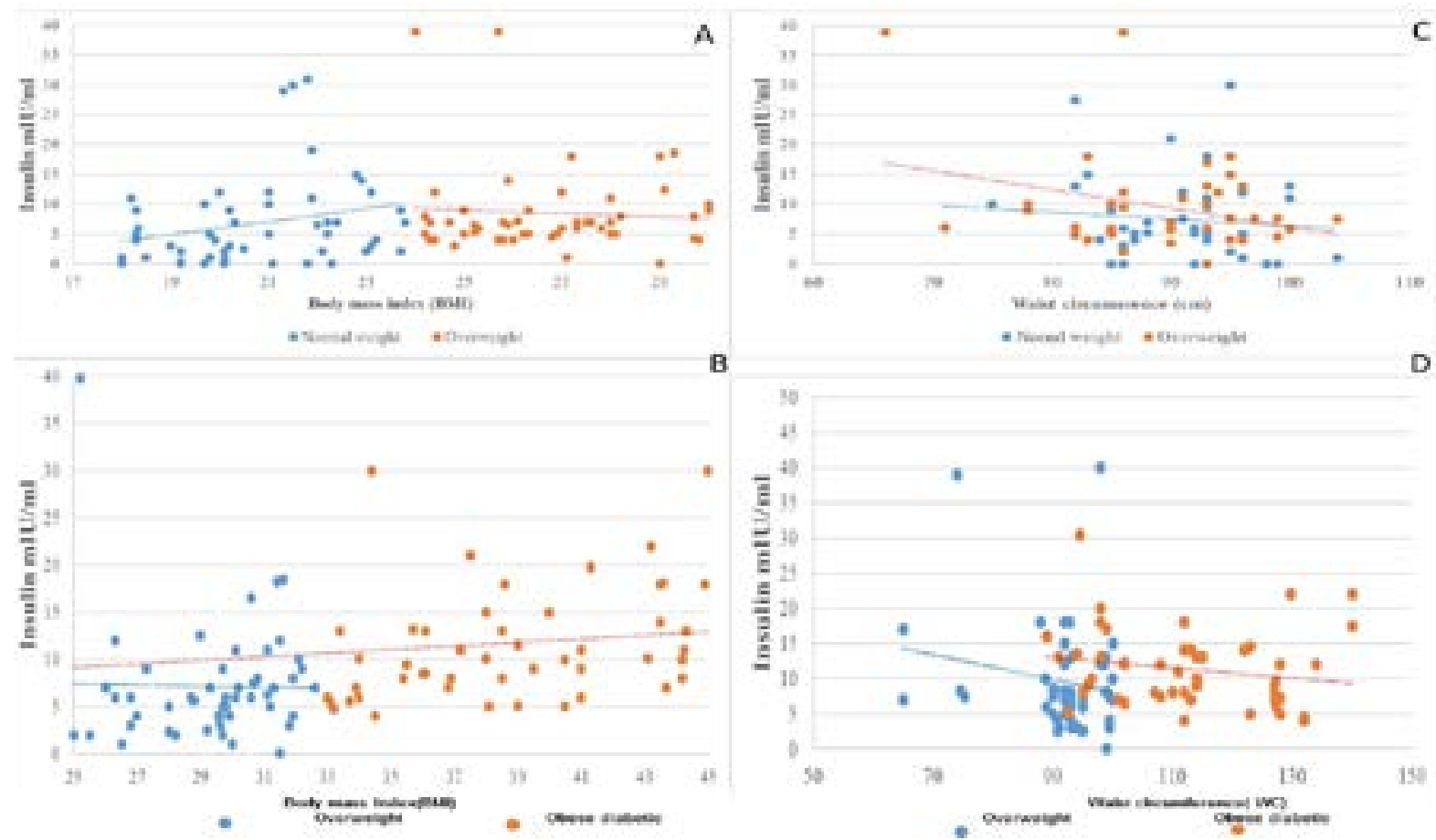

Fig.1: The distribution between Insulin hormone, BMI and WC among the study group A: Correlation between the Insulin hormone and BMI in normal weight and overweight B: Correlation between the Insulin hormone and BMI in overweight and obese diabetic C: Correlation between the Insulin hormone and WC in normal weight and overweight and D. Correlation between the Insulin hormone and WC in overweight and obese diabetic 

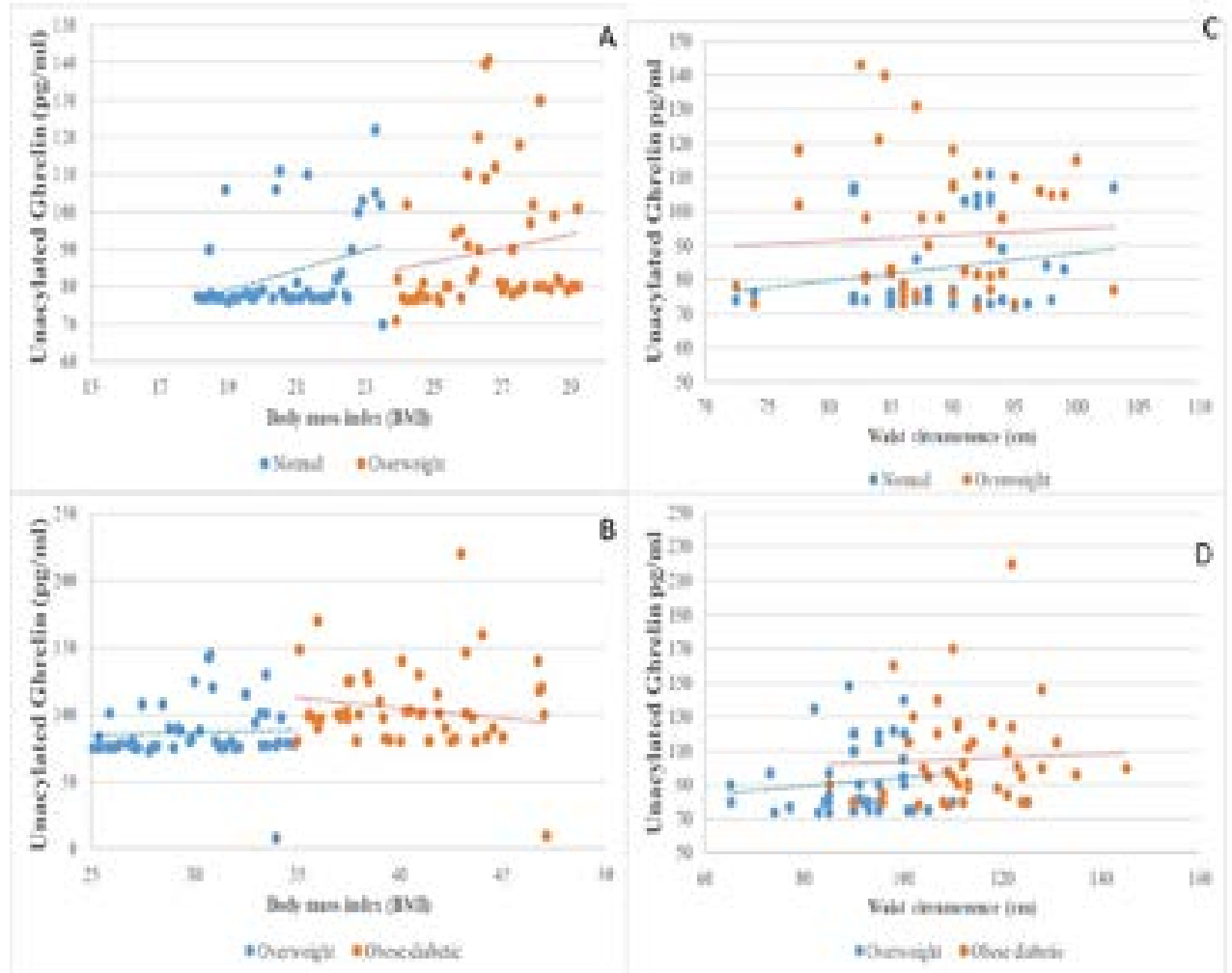

Fig.2: The distribution between Grehlin hormone, BMI and WC among the study group A: Correlation between the Grehlin hormone and BMI in normal weight and overweight B: Correlation between the Grehlin hormone and BMI in overweight and obese diabetic C: Correlation between the Grehlin hormone and WC in normal weight and overweight. D: Correlation between the Grehlin hormone and $\mathrm{WC}$ in overweight and obese diabetic 

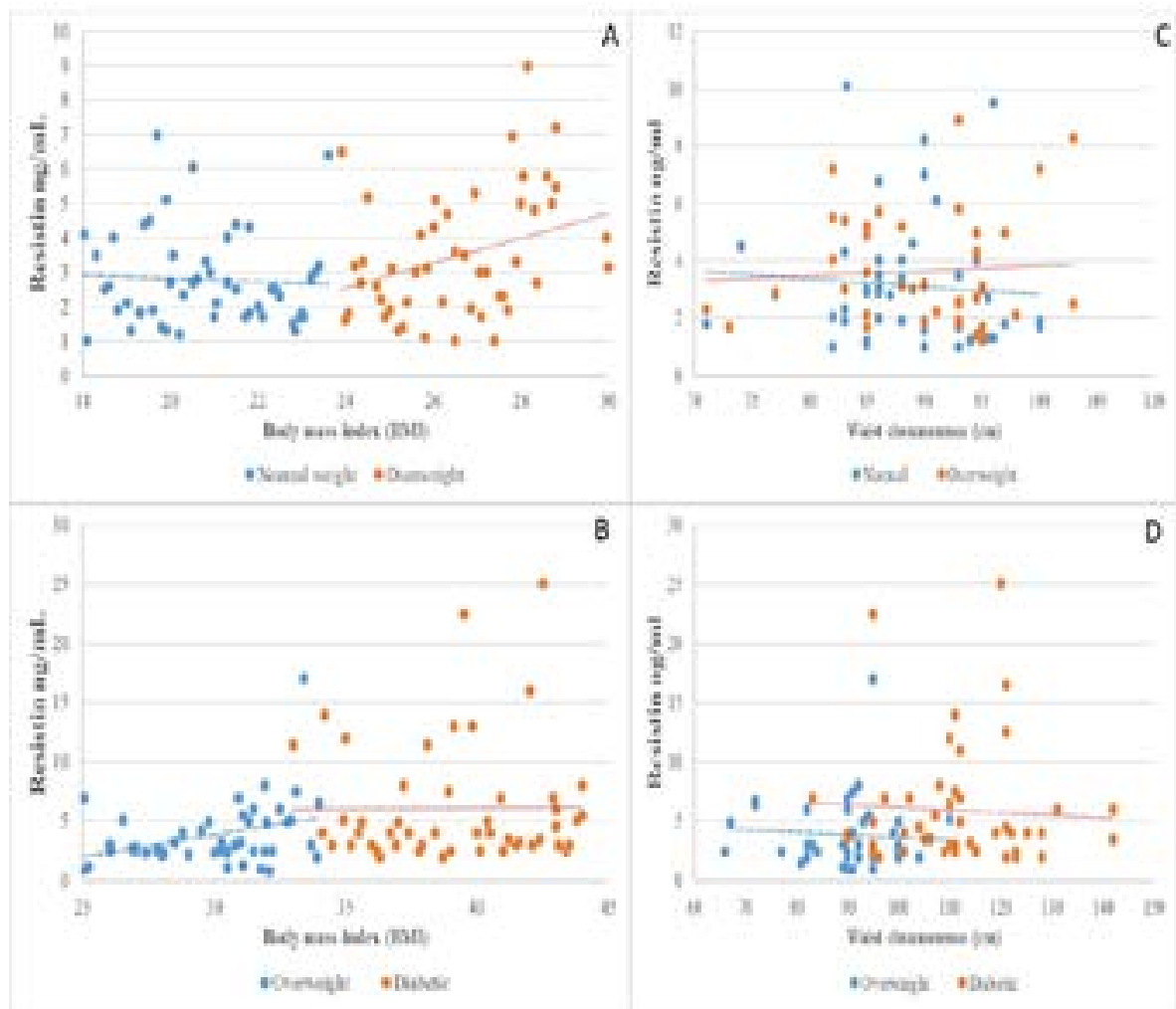

Fig.3: The distribution between Resistin hormone, BMI and WC among the study groups A: Correlation between the Resistin hormone and BMI in normal weight and overweight $\mathbf{B}$ : Correlation between the Resistin hormone and BMI in overweight and obese diabetic C: Correlation between the Resistin hormone and WC in normal weight and overweight $\mathbf{D}$ : Correlation between the Resistin hormone and WC in overweight and obese diabetic

Figures $(1 ; 2$ and 3$)$ illustrate the correlations between the means level of measured hormones with BMI andWC of the study groups. The mean of hormonal levels of insulin, resistin and ghrelin increase with increasing BMI and WC values for the study participants.

\section{Discussion}

The present study indicated that the level of insulin, resistin and ghrelin are higher in obese T2D. subjects when compared with lean and overweight subjects. These results correlate positively with obesity and mark an important link between obesity and related metabolic syndrome.

Nonetheless, the main findings of the current study verified significant positive correlation between BMI and Insulin in overweight and obese T2D women. In addition, insulin levels were significantly high in obese diabetic group, which confirmed that obesity in women is associated with hyperinsulinaemia and insulin resistance. These results are explained by the close relation between BMI WC and body fat content or by the overall significance of abdominal fat. These findings might likely refer basically to several mechanisms that could verify or show how visceral adiposity in obese subjects, could lead to insulin resistence IR. On the other hand, fat deposits areas, mainly visceral fat, released free fatty acids (FFA).These acids can block the insulin signal pathways directly and intersected insulin secretion as well as insulin action. ${ }^{12}$ Moreover, increased amounts of FFA in the portal circulation may impair the metabolism and action of Insulin and directly increase gluconeogenesis in the liver. ${ }^{13}$ The correlation coefficient between the insulin and WC in normal weight and overweight women demonstrated that, there is overlap of the scatter of insulin values and exhibited no significant difference between the two groups, $(p=0.297)$. The correlation between the 
insulin and WC in overweight and obese (T2D) women has shown that, the hormone has significant difference when the two groups were compared $(p=.020)$. These findings are in accordance with other studies showing elevated serum insulin levels in obese subjects. ${ }^{1,12}$ Similar findings were established in Egypt ${ }^{14}$ and in Saudi women. ${ }^{15}$ Correlation between resistin and BMI revealed that resistin level is slightly higher in obese T2D women when compared with both over-weight and lean subjects. The consequences might refer to the low levels of of adipose tissue in overweight when compared to the obese diabetic participants. Therefore, overweight subjects do not show a significant rise in resistin compared to normal individuals.

However, obese diabetic subjects show significant rise in resistin which is in agreement with the insulin resistance in T2D patients. These results are consistent with the studies completed in Saudi women and others in Jordan who reported higher resistin levels were observed in patients with T2D and were correlated with insulin resistance and obesity proposing that resistin might contribute to the development of T2D in humans. ${ }^{15}$ Later, several recent researches in humans have shown that higher serum resistin in obese patients was linked to obesity concentrations when compared with lean subjects. This outcome was found to be positively associated with visceral fat area and changes occurring in BMI. ${ }^{16}$ Contrasting studies in Caucasian and non-Caucasians populations show divergent outcome suggesting the role for resistin in obesity. ${ }^{17}$ Nonetheless, different studies have supported increased resistin expression with adiposity and others have shown a significant decrease in revolving resistin concentrations. These findings were noticed to be found accompanied with the moderate weight loss and post-gastric bypass. No plasma levels of resistin with markers of adiposity was reported. ${ }^{18}$ However, the present data regarding resistin adds to a growing body of evidence that resistin is strongly expressed in human visceral fat chambers and is more highly affected by WC and BMI. Thereupon, these results recommended that $\mathrm{WC}$ is an adequate rightious index for visceral fat cumulation and can therefore, be used as a sensitive indicator of health hazards correlated with visceral obesity. This outcome also confirms that resistin is an important hormone in human adipose tissue. Our results go in the same trends with Guo. ${ }^{19}$
The current study showed that ghrelin levels scored higher concentrations in obese subjects than in health bodies. The results go in the same line of the studies conducted in human by Al-Hakeim. ${ }^{20}$ Similar findings were found in Caucasian and Pima Indian individuals ${ }^{21}$,Egypt ${ }^{14}$ and in Saudi females. ${ }^{15}$ Regarding our data higher ghrelin levels were recorded in obese subjects when compared with the lean and overweight. This may be either due to obesity and its complications, or partly due to the active feedback that enhances appetite and body weight, but not the main cause of obesity. This could be supported by the fact that circulating ghrelin levels increased in anorexia nervosa, syndrome and cachexia. ${ }^{22}$ These data seem to elucidate that ghrelin served as a regulatory tool in human obesity.Thereupon, this tactic may disprove the result of elevated insulin. This could be attributed to, the levels of fasting plasma ghrelin which are positively correlated with insulin fasting plasma levels.

Therefore, the adequacy of plasma ghrelin concentrations resulted in initiating obesity and this may also imply a physiological adaptation to the positive energy balance that correlated with obesity occurrence. Further information is critically needed to probe the exact effect of ghrelin and why ghrelin sufficiency occurs in obese individuals. Several studies have asserted that the mechanism of obesity is still unclear. Uncontrolled diabetes leads to increase both revolving ghrelin concentrations and behavioral sensitivity to ghrelin. Although plasma ghrelin concentrations fall in response to hyperphagic feeding. These outcomes support the hypothesis that high lighted increased ghrelin signaling contributes to the pathogenesis of diabetic hyperphagia. ${ }^{23}$ Despite using the pearson correlation test, it is worthy noting that there is no significant correlation among the serum concentrations of studied hormones in all study groups specifically obese with T2D subjects. These results indicate very weak interrelationship among them.No interrelationship between hormones could be explained by the small number of patients involved in the study. Interestingly, the relationship of insulin, ghrelin and resistin in normal, over weight and obese T2D women have been reported for the first time in Sudan and our findings could be indorsed as the baseline data for future studies and population health care.

\section{Conflict of interest disclosure}

All authors declare that no conflict of interest exists for this work. 


\section{Acknowledgment}

I would like to thank Prof. Mohammed Ahmed Bakheit, Dept. of Parasitology Univ. of Khartoum, who helped in finalizing this work. Deepest gratitude to Prof. Hamid Isamil, Department of Animal Sciences, North Carolina Agricultural and Technical State University, who helped in diagram drawing and the statistical analysis. Warm thanks to Dr. Lorina Badger- Emeka, Dept. of Microbiology, King Faisal University for her help in editing.

\section{References}

1. Roberts CK, Hevener AL, Barnard RJ. Metabolic syndrome and insulin resistance: underlying causes and modification by exercise training. Comprehensive Physiology. 2013. Available from: https://www.ncbi.nlm.nih.gov/ pubmed/23720280;doi: 10.1002/cphy.c110062

2. Nakashima A, Yokoyama K, Kawanami D, Ohkido I, Urashima M, Utsunomiya K, et al. Association between resistin and fibroblast growth factor 23 in patients with type 2 diabetes mellitus. Scientific Reports. 2018;8. Available from: https://www.ncbi.nlm.nih.gov/pmc/articles/ PMC6143599/

3. Alissa EM, Alzughaibi LS, Marzouki ZM. Association between serum resistin, adiposity measures and inflammatory makers in women without cardiovascular diseases. Chemistry and Physics of Lipids. 2019;218:13640. Available from: https://www.sciencedirect.com/ science/article/pii/S000930841830135X;https://doi. org/10.1016/j.chemphyslip.2018.12.005

4. Eissa N, Ghia J. Immunomodulatory effect of ghrelin in the intestinal mucosa. Neurogastroenterology \& Motility. 2015;27(11):1519-27. Available from: https://www.ncbi. nlm.nih.gov/pubmed/26503163

5. Chanoine J, De Waele K, Walia P. Ghrelin and the growth hormone secretagogue receptor in growth and development. International Journal of Obesity. 2009;33(S1):S48. Available from: https://www.nature.com/articles/ ijo200917

6. Horvath T, Tschöp M. Ghrelin. 2015, Available from: https://www.ncbi.nlm.nih.gov/pmc/articles/ PMC4443295/

7. Choi YJ, Kim N, Yoon H, Shin CM, Park YS, Park JH, et al. Increase in plasma acyl ghrelin levels is associated with abatement of dyspepsia following Helicobacter pylori eradication. Journal of Gastroenterology. 2016;51(6):54859. Available from: https://www.ncbi.nlm.nih.gov/ pubmed/26412402
8. Lu Y, Dang S, Wang X, ZhangJ, Zhang L, Su Q, et al. NO involvement in the inhibition of ghrelin on voltage-dependent potassium currents in rat hippocampal cells. Brain Research. 2018;1678:40-6 PubMed . Available from: https://www.ncbi.nlm.nih.gov/pubmed/28987626

9. Aleidi S, Issa A, Bustanji H, Khalil M, Bustanji Y. Adiponectin serum levels correlate with insulin resistance in type 2 diabetic patients. Saudi Pharmacentical Journal. 2015;23(3):250-6. Available from: https://www.ncbi.nlm. nih.gov/pmc/articles/PMC4475813/

10. Jaganathan R, Ravindran R, Dhanasekaran S. Emerging role of adipocytokines in type 2 diabetes as mediators of insulin resistance and cardiovascular disease. Canadian Journal of Diabetes. 2018;42(4):446-56. e1. Available from: https://www.sciencedirect.com/science/article/ abs/pii/S1499267117303349;https://doi.org/10.1016/j. jcjd.2017.10.040

11. WHO. Obesity and overweight. 2018. Available from: https://www.who.int/news-room/fact-sheets/detail/ obesity-and-overweight

12. González-Saldivar G, Rodríguez-Gutiérrez R, Ocampo-Candiani J, González-González JG, Gómez-Flores M. Skin Manifestations of Insulin Resistance: From a Biochemical Stance to a Clinical Diagnosis and Management. Dermatology and Therapy. 2017;7(1):37-51.

Available from: https://www.ncbi.nlm.nih.gov/pmc/articles/PMC5336429/

13. Cersosimo E, Triplitt C, Mandarino LJ, DeFronzo RA. Pathogenesis of type 2 diabetes mellitus. 2015; Available from: https://www.ncbi.nlm.nih.gov/ pubmed/15925010. DOI: 10.1016/j.arcmed.2005.01.003. 14. Kamal M, Mohi A, Fawzy M, El-Sawah H. Fasting plasma ghrelin in women with and without PCOS. Middle East Fertility Society Journal. 2010;15(2):91-4.

Available from: https://www.sciencedirect.com/science/ article/.../S111056901000044...

15. Alharbi M, Jackson RT. Factors associated with obesity among Saudi women of reproductive age in Jeddah City. J Obes Overweig. 2017;3(1):106. Available from: www. annexpublishers.co/.../3106-

16. Jung UJ, Choi M-S. Obesity and its metabolic complications: the role of adipokines and the relationship between obesity, inflammation, insulin resistance, dyslipidemia and nonalcoholic fatty liver disease. International Journal of Molecular Ssciences. 2014;15(4):6184-223. Available from: https://www.ncbi.nlm.nih.gov/pubmed/24733068 17. Conroy SM, Chai W, Lim U, Franke AA, Cooney RV, 
Maskarinec G. Leptin, adiponectin, and obesity among Caucasian and Asian women. Mediators of Inflammation. 2011;2011. Available from: https://www.hindawi.com/ journals/mi/2011/253580/abs/,

18. Jamaluddin MS, Weakley SM, Yao Q, Chen C. Resistin: functional roles and therapeutic considerations for cardiovascular disease. British Journal of Pharmacology. 2012;165(3):622-32. Available from: https://www.ncbi. nlm.nih.gov/pubmed/21545576

19. Guo S-x, Zhang X-h, Zhang J-y, He J, Yan Y-z, Ma $\mathrm{J}-1$, et al. Visceral adiposity and anthropometric indicators as screening tools of metabolic syndrome among low income rural adults in Xinjiang. Scientific Reports. 2016;6:36091. Available from: https://www.ncbi.nlm.nih. gov/pubmed/27782221

20. Al-Hakeim H, Ali M. Low ghrelin level is associated with poor control and bad prognosis parameters in obese diabetic patients. J Diabetol. 2012;1:5. Available from: www.journalofdiabetology.org/article.asp?issn=2078...
21. Meena VP, Seenu V, Sharma M, Mallick SR, Bhalla AS, Gupta N, et al. Relationship of adipocyte size with adiposity and metabolic risk factors in Asian Indians. PLoS One. 2014;9(9):e108421. Available from: https://www. ncbi.nlm.nih.gov/pmc/articles/PMC4177391/ 22. Cheung W-H, Pucci A, Batterham RL. Gut-Derived Hormones and Energy Homeostasis. Obesity, Bariatric and Metabolic Surgery: Springer, 2016. p. 21-8. Available from: https://link.springer.com/chapter/10.1007/978-3-319-04343-2_3.

23. El-attar. ghrelin in obese type 2 diabetic Egyptian female patients Chemical Pathology Department, Medical Research Institute Alexandria University, World congress on insulin resistance, diabetes and cardiovascular disease. 2010; PMCID: PMC4538889. Available from: https:// www.ncbi.nlm.nih.gov/pmc/articles/PMC4538889/

24. Organization WHO. Preventing and managing the global epidemic of obesity. Report of the World Health Organization Consultation on Obesity Geneva: World Health Organization. 1997. 